\title{
The relationship of puberty to other maturity indicators and body composition in man
}

\author{
W. A. Marshall \\ Department of Human Sciences, University of Technology, \\ Loughborough, Leicestershire LE11 3TU, U.K.
}

The purpose of this paper is to examine the relationship between sexual development and other maturational processes in children. The word 'puberty' is used as a general term to include the development of the secondary sex characters and the attainment of reproductive competence.

\section{Puberty}

At puberty, in boys and girls, the development of the gonads is accompanied by accelerated somatic growth (the adolescent spurt: see Text-fig. 1), changes in the quantity and distribution of fat in the body, the development of the secondary sex characters, and other physiological events. Children vary greatly in the age at which these changes begin and in the time which elapses from their onset to their completion.

The mean growth rate just before the adolescent spurt begins is about $5 \mathrm{~cm}$ per year in both sexes. (Growth rate, in stature, is usually expressed in 'centimetres per year' although a given rate need not be maintained for a whole year.) When the spurt begins, the curve of growth velocity plotted against age rises steeply to a maximum (usually referred to as 'peak height velocity' or PHV) and then immediately begins to fall again (Text-fig. 1); there is no plateau during which the maximum growth rate is maintained. The peak height velocities of girls are usually between 7 and $11 \mathrm{~cm}$ per year, while those of boys vary approximately between 7.5 and $13.0 \mathrm{~cm}$ per year.

The mean age at PHV of a group of English girls was $12 \cdot 14 \pm 0 \cdot 14$ years with a standard deviation of 0.88 years (Marshall \& Tanner, 1969). The mean age of boys at PHV was $14.06 \pm 0.14$ years with a s.d. of 0.92 years (Marshall \& Tanner, 1970). Therefore the adolescent spurt occurs, on the

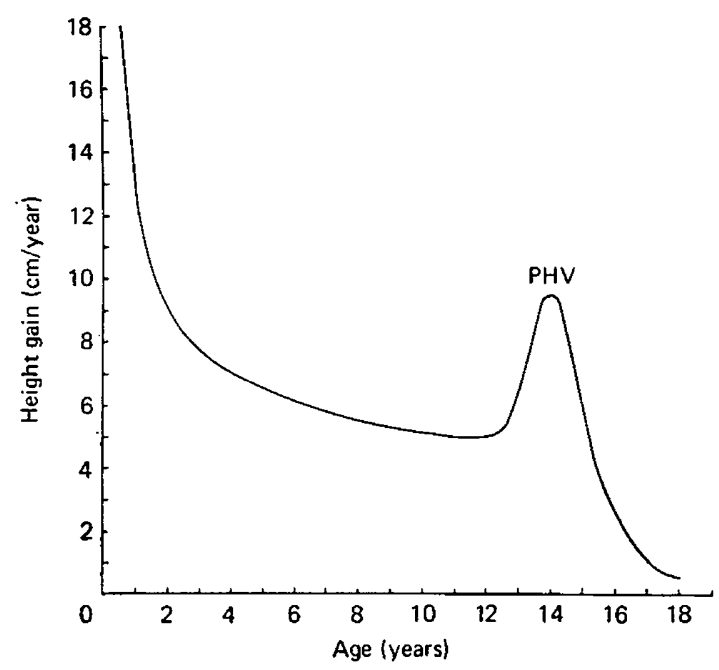

Text-fig. 1. Rate of growth of a typical boy plotted against age. Note the adolescent spurt beginning, in this case, at about 12 years of age and reaching Peak Height Velocity (PHV) at age 14 years. (Reproduced from Marshall, 1970.) 


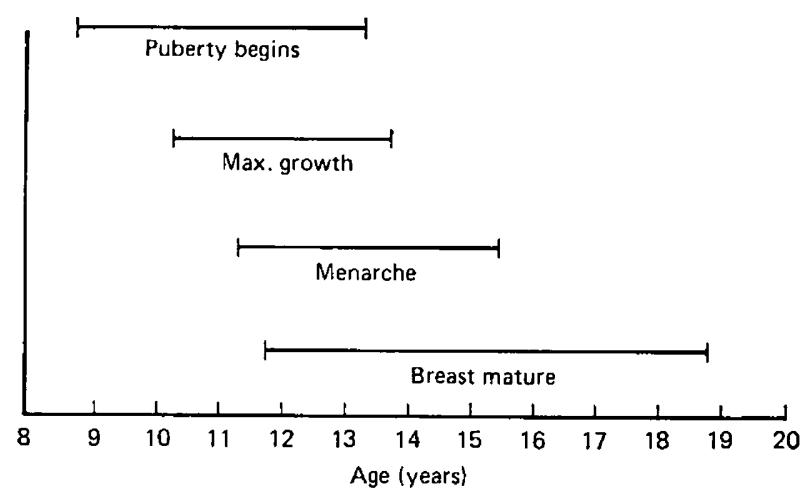

Text-fig. 2. Range of ages within which European girls reach given stages of puberty. 'Puberty begins' refers to the first appearance of either breast development or pubic hair growth, whichever appears first in the individual child. 'Maximum growth' equals Peak Height Velocity. (Reproduced from Marshall, 1971.)

average, about 2 years earlier in girls than in boys. However, the range of variation of ages within which $95 \%$ of children may reach PHV is approximately 4 years for either sex. Hence, girls who reach PHV at a later age than average, i.e. between approximately 12 and 14 years, will do so later than some early maturing boys.

There is a similar variation in the age at which boys attain a given stage of genital development and girls attain menarche or a given stage of breast development (Text-fig. 2). Thus a child's age is a very poor index of his or her progress towards, or beyond, PHV or any other of the changes which take place at puberty.

Thus puberty is not an 'event' but a number of different changes occupying a number of years and varying considerably in the age at which they occur. They vary also in relationship to each other. For example, some girls have well developed breasts before they have any growth of pubic hair while others have considerable growth of pubic hair before their breasts begin to develop (Marshall \& Tanner, 1969).

Once the changes of puberty have begun there is still considerable variation in the time which different individuals take to pass through them. Some do so in less than 2 years whilst others take more than 5 . There are no well documented instances in which menarche has occurred before PHV but it usually occurs while growth is decelerating rapidly. This suggests, but does not provide sufficient evidence for, a common cause for menarche and the deceleration of growth. The relationship between the growth spurt and the secondary sex characters is different in the two sexes. Girls usually reach PHV while their breasts are in an early stage of development but boys do not do so until their genitalia are approaching maturity.

The changes which we include within the term 'puberty' are indices of maturity in the sense that their completion usually indicates that the attainment of full reproductive capacity is near and that skeletal growth is nearing its end. It is very difficult to ascertain when girls actually become able to conceive but it is probably some time after menarche in most cases. The most important characteristic of any satisfactory parameter of maturity is that its final (i.e. mature) state must be known. For practical purposes this implies that the parameter reaches the same end point (e.g. the ability to reproduce) in all normal subjects.

\section{Body size and maturity}

Stature and weight are not satisfactory indices of maturity in children. Consider, for example, a girl whose weight is $50 \mathrm{~kg}$. The normal range of variation in weight is such that she might be a normal but unusually heavy ( 97 th centile) child aged about 11 years and near the beginning of her adolescent growth spurt. In this case her sexual development would probably have begun but she would not yet have experienced menarche. At the other extreme, she might be a rather small but completely mature 
woman aged 19 or more who had been menstruating for a number of years. She might, of course, be anywhere between these two extremes. Weight would only be a useful index of maturity if all individuals, at least of the same sex, were to reach the same final weight. Then, when we weighed a child, we could say "this weight is $x \%$ of the final weight which all girls reach, therefore she is $x \%$ mature". In fact, the weights of healthy young women at the cessation of their growth vary between approximately 45 and $75 \mathrm{~kg}$. Therefore the weight at maturity of some girls is only about $72 \%$ of the weight which other girls may reach before they are mature. Similar arguments may be applied to boys and to the use of stature as a maturity index in either sex.

The changes of puberty may be used as indices of maturity in relation to both reproductive capacity and growth but clearly cannot be of any value before they have begun. Some parameter which could be observed during the whole childhood would therefore be more useful.

\section{Skeletal maturity}

The ossification of the skeleton provides a sequence of changes which can be studied radiographically throughout childhood. New centres of ossification appear and then their shapes alter in recognizable ways. Finally, the epiphyses of long bones unite with their shafts. This end result is common to all boys and girls when their skeletal development is complete. Various techniques have been described for estimating skeletal maturity and expressing it as a 'bone age'. The techniques most widely used at present are those of Tanner, Whitehouse, Marshall, Healey \& Goldstein (1975) and Greulich \& Pyle (1959), but both are far from perfect. 'Bone age' is of some value in assessing a child's progress through the growth process and in predicting his adult height.

However, bone age is of little value in predicting when the secondary sex characters will develop. Marshall (1974) observed that the skeletal ages of girls whose breasts were just beginning to develop varied between 8 and 14 years, i.e. a similar range of variation to that of their chronological ages. At most stages of sexual development, in both girls and boys, the variations in skeletal and chronological age differed very little from each other (see Text-fig. 3). However, in girls who were X-rayed shortly before or after menarche, the standard deviation of skeletal age $(0.39$ 'years') was significantly less

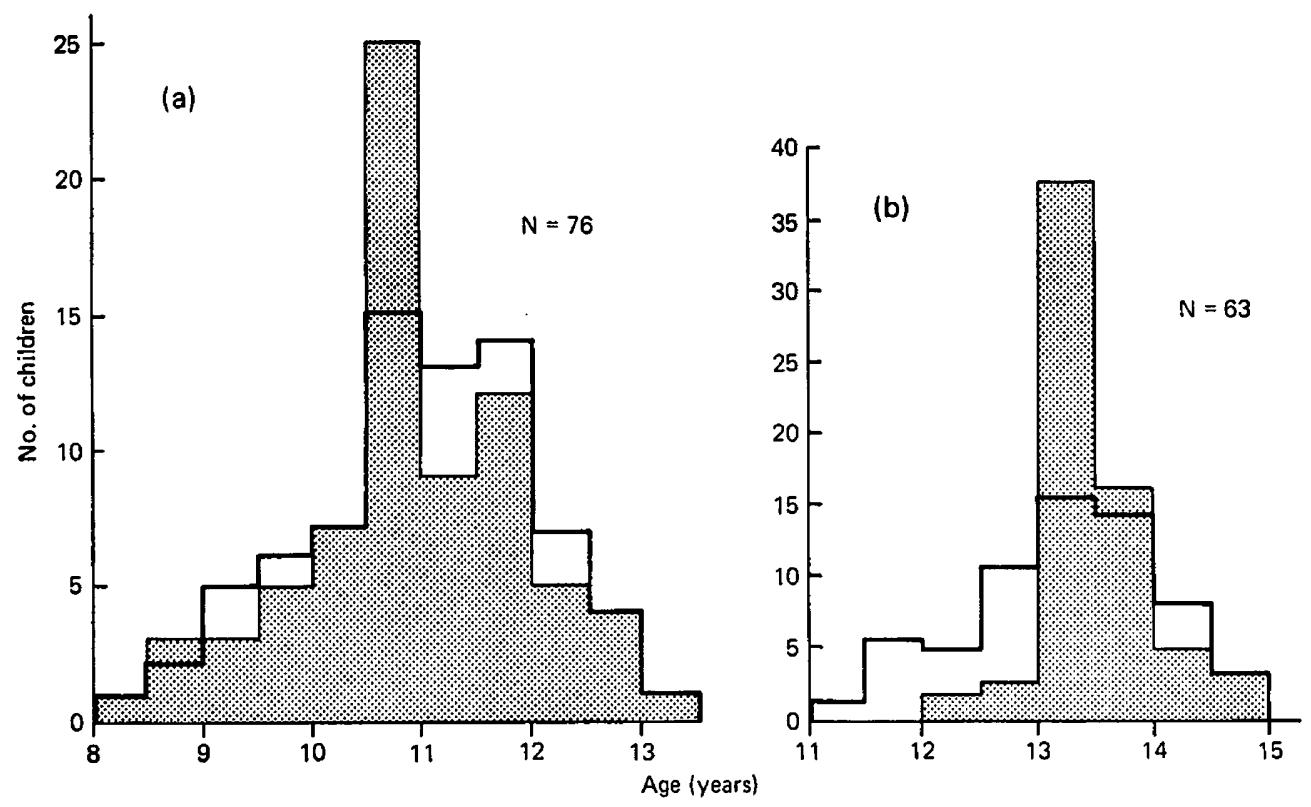

Text-fig. 3. Distribution of chronological age (heavy outline) and skeletal age (shaded columns) in girls within a few weeks of (a) breast development and (b) menarche. Based on data from Marshall (1974) and from W. A. Marshall unpublished. 
than that of their chronological ages at the time when the radiography was carried out. Thus skeletal age was shown to be better than chronological age alone for predicting age at menarche. The relevant prediction equations, with estimates of the error of prediction, in girls of different ages are presented by Marshall \& Limogni (1976).

\section{Body composition}

During recent years there has been some controversy about the relationship of body weight and body composition to puberty and, in particular, to menarche. Young, Sipin \& Roe (1968) observed that girls who had not reached menarche had smaller measurements of several circumferences than those who had begun to menstruate, regardless of chronological age. The greatest increase in circumferences with advancing sexual development occurred in the buttocks $(21 \cdot 3 \%)$, thighs $(20 \cdot 7 \%)$ and lower abdomen $(18 \cdot 4 \%)$.

Tanner (1965) demonstrated, by a radiographic technique, that there is a marked increase in the width of bone and muscle in boys' limbs during adolescence and that this is usually accompanied by a simultaneous loss of fat. The muscle widths of boys and girls showed maximal velocities coincident with, or slightly after, PHV. In boys the upper arm, calf and thigh all showed loss of fat which was greatest at the time of PHV. Girls lost fat only from the upper arm but there was a slowing in the rate of gain of fat on the thigh and calf, the gain being slowest at PHV and hence some time before menarche. The buttocks and lower abdomen were not studied.

The amount and distribution of water in the body changes at adolescence. The contribution of water to body weight increases by about $5 \%$ in males and decreases by a similar amount in females between 12 and 17 years of age.

Estimates of lean body mass (LBM), derived from potassium- 40 counts, change with age according to curves which are closely parallel to those of height and weight. During adolescence in males there is an abrupt increase which is relatively greater than that in total body weight since the fat content of the body decreases. In females, LBM increases more gradually (Forbes, 1965). The decreasing contribution of muscle mass to body weight in females during adolescence and into young adulthood, probably reflects accumulation of fat.

Frisch \& Revelle (1969), observed that, when girls in three separate studies were grouped according to age at PHV, or age at menarche, the mean height at PHV of each group increased as the age increased, e.g. from $142.7 \pm 1.8 \mathrm{~cm}$ at 10.2 years to $155.7 \pm 2.8 \mathrm{~cm}$ at 13.8 years. However, the mean weight at peak weight velocity (about $39 \mathrm{~kg}$ ) did not vary significantly between age groups and regression of weight at peak velocity on age at peak velocity did not differ significantly from zero. The authors suggested that the attainment of a specific weight associated with the peak of the adolescent spurt may be critical for menarche. Later Frisch \& Revelle $(1970,1971)$ studied height and weight at menarche for each subject in the three longitudinal growth studies. Early and late maturing girls had menarche at the same mean weight although late maturers were taller. The beginning of the spurt in weight gain and maximum rate of weight gain also occurred at 'invariant' mean weights. They proposed that a critical body weight might trigger each of these adolescent events.

An observation that the mean weight at menarche of 30 undernourished girls did not differ from that of 30 well nourished controls, although the undernourished girls attained menarche 2 years later than controls and at a slightly greater mean height, has been taken as further evidence for 'the weight dependency of menarche' (Frisch, 1972).

However, it was later suggested that body composition was more important than weight. Frisch, Revelle \& Cooke (1973) used the equation of Mellits \& Cheek (1970) to calculate total body water from measurements of height and weight. Early and late maturing girls did not differ in mean total water. The coefficient of variability at menarche of (total body water/total body weight) was less than that of weight alone. During the interval from the initiation of the growth spurt to menarche, the ratio of fat to lean body weight changed from $1: 5$ to $1: 3$. The authors suggested that the changes in body composition which accompany puberty are in accord with the hypothesis that a critical metabolic rate triggers menarche. 
However, a hypothesis cannot be justified on the basis only of evidence which seems to confirm it. It must be shown also that critical tests designed to refute it have been unsuccessful, and that the data on which it is based are irrefutable. The initial concept of a 'critical body weight' at menarche does not stand up to examination. The weight at menarche of girls from 8 independent samples varied by $71.4 \mathrm{~kg}$ (i.e. $25 \cdot 9-97 \cdot 3 \mathrm{~kg}$ ) and the mean weights of the 8 samples also varied, from $39 \cdot 8$ to $55.0 \mathrm{~kg}$ (Johnston, Roche, Schell \& Wettenhall, 1975). These authors also suggested that the reduction in variability which was observed when body water was substituted for body weight might result from a statistical artefact. They point out that Frisch and her colleagues did not measure total body water in any of their subjects but estimated it from an equation, based on height and weight, with a standard error of estimate of 1.65 litres. They ignored this error factor when they observed a reduction of $5.2 \%$ in the coefficient of variation of the estimated total body water in girls at menarche. However, the unjustified elimination of the variance due to the standard error of estimate could account in theory for a reduction of $6 \cdot 2 \%$.

Billewicz, Fellowes \& Hytten (1976) also argued that an apparent relationship between body composition and menarche followed directly from arithmetical operations on height and weight. They emphasized the dangers of drawing biological conclusions from derived, as opposed to observed, data. Their own data, from girls in Newcastle-upon-Tyne, showed that at all ages the variation of body weight at menarche was as large as that amongst non-menstruating girls. Menarche occurred in bedridden mentally retarded girls long before they reached the 'critical' weight of $47 \cdot 8 \mathrm{~kg}$ although ambulatory mentally retarded girls did conform more closely to this weight. A further survey of girls with various disorders of growth and body composition led to the conclusion that menarche is not necessarily triggered by achievement of a critical body weight or lowering of metabolism (Osler \& Crawford, 1973; Crawford \& Osler, 1975), although the data were in accord with the generalization that, when the ovaries are competent, menarche is highly correlated with achievement of a characteristic body composition. However, correlation need not imply a causal relationship. Eight-year-old girls with simple obesity were an exception and had a greater percentage of fat than normal menarchial girls but showed no signs of puberty.

Cameron (1976) suggested that, if the critical body weight hypothesis of Frisch \& Revelle (1970) were true, weight and skinfold measurements would be less variable at menarche than before or after. He did not observe such a reduction in 36 girls, studied longitudinally. The coefficient of variation at 1 year before menarche was $11.3 \%$ and at 1 year after menarche $12.1 \%$, compared with the menarchial value of $12.5 \%$. The variability of skinfold thickness increased gradually until 1 year after menarche. If body fat were critical for the occurrence of menarche we might expect a reduction of the variability of the skinfolds, unless quite unrealistic changes in deep body fat were to take place.

\section{Prediction of age at menarche}

If it were possible to predict age at menarche from the body composition of premenarchial girls, this would suggest that changes in body composition and the events which lead to menarche were manifestations of parallel (although not necessarily causally related) maturational processes. Frisch (1974) introduced a method for predicting the age of menarche of girls at each age from 9 to 13 years. She used height and weight to estimate body water which, in turn, was taken as an indicator of body composition, particularly fatness. A similar method to predict age at initiation of the adolescent growth spurt from the height and weight of a girl at age 8 years was also given. Frisch suggested that the accuracy of these predictions supported the idea that the ratio of the lean body weight to fat was important for the determination of sexual maturation. However, Marshall \& Limogni (1976) demonstrated that the parameters used by Frisch did not lead to a significantly more accurate prediction than that which could be made from chronological age alone. They drew attention to the fact that the possible range of variation in age at menarche decreases as the age of pre-menarchial girls increases. For example, on the assumption that menarche usually occurs between the ages of 11 and 15 with a mean age of 13 years, we could say that a pre-menarchial 10-year-old would probably menstru- 
ate between these ages, i.e. within a range of 4 years. However, in the case of a pre-menarchial girl who had already reached her 14th birthday, the menses would probably begin in the following year. Thus the range of possible error of a prediction of menarchial age diminishes with the age of the premenarchial subject. The parameters used by Frisch did not lead to an appreciably greater reduction in error than that which results from increase in chronological age alone. Skeletal age, used in the form of the difference between bone age and chronological age (bone age being calculated by the method of Tanner et al., 1975) did reduce the error of prediction in some age groups (Marshall \& Limogni, 1976).

\section{Conclusion}

The available evidence does not justify the view that the occurrence of menarche is related to the attainment of a particular height, weight or body composition. Menarche does bear some relationship to the maturation of the skeleton and to growth. It almost invariably occurs after the peak of the adolescent growth spurt. However, this point in the growth curve is reached at widely differing heights and weights in different girls, according to the variation in their final sizes. It is perhaps interesting to speculate as to what the effect of eliminating this variation might be. If a breed of children were produced with the same genetic uniformity as we expect from our breeds of cattle, and they were brought up in identical environments, as many groups of domestic animals are, what would be the outcome? Would they pass through their growth curves at almost identical rates, as identical twins may do (Tanner, 1962)? If so we might expect them to reach PHV and menarche at the same age, height, weight and body composition. I hope that no-one will ever have the opportunity to study this phenomenon in children, but we should recognize that a similar one is occurring in our domestic animals and that the relationships we observe between sequential events in their development may only be artefacts due to the elimination of variation by both genetic and environmental control.

\section{References}

Billewicz, W.Z., Fellowes, H.M. \& Hytten, C.A. (1976) Comments on the critical metabolic mass and the age of menarche. Ann. hum. Biol. 3, 51-59.

Cameron, N. (1976) Weight and skinfold variation at menarche and the critical body weight hypothesis. Ann. hum. Biol. 3, 279-282.

Crawford, J.D. \& OsLER, D.C. (1975) Body composition at menarche: the Frisch-Revelle hypothesis revisited. Pediatrics 56, 449-458.

Forbes, G.B. (1965) Towards a new dimension in human growth. Pediatrics 36, 825-835.

FRISCH, R.E. (1972) Weight at menarche: similarity for well-nourished and undernourished girls at differing ages, and evidence for historical constancy. Pediatrics $50,445-450$.

FrisCH, R.E. (1974) A method of prediction of age of menarche from height and weight at ages 9 through 13 years. Pediatrics 53, 384-390.

FRISCH, R.E.\& Revelle, R. (1969) The height and weight of adolescent boys and girls at the time of peak velocity of growth and height and weight : longitudinal data. Hum. Biol. 41, 536-559.

Frisch, R.E. \& ReVelle, R. (1970) Height and weight at menarche and a hypothesis of critical body weights and adolescent events. Science, N. Y. 169, 397-399.

Frisch, R.E. \& Revelle, R. (1971) The height and weight of girls and boys at the time of initiation of the adolescent growth spurt in height and weight and the relationship to menarche. Hum. Biol. 43, 140-159.
Frisch, R.E., Revelle, R. \& Cook, S. (1973) Components of weight at menarche and the initiation of the adolescent growth spurt in girls : estimated total water, lean body weight and fat. Hum. Biol. 45, 469-483.

Greulich, W.W. \& Pyle, S.I. (1959) Radiographic Atlas of Skeletal Development of the Hand and Wrist, 2nd edn. Stanford University Press.

Johnston, F.E., Roche, A.F., Schell, L.M. \& WettenHALL, N.B. (1975) Critical weight at menarche; critique of a hypothesis. Am. J. Dis. Child. 129, 1923.

Marshall, W.A. (1970) Physical growth and development. In Brennemann's Practice of Pediatrics, Vol. 1 Ed. V. C. Kelley. Harper \& Row, Hagerstown. Maryland.

MARshall, W.A. (1971) Somatic development and study of the central nervous system. In Normal and Abnormal Development of Brain and Behaviour, pp, 1-15. Eds G. B. A. Stoelinga \& J. J. van der Werff ten Bosch. Leiden University Press.

MARShalL, W.A. (1974) Interrelationships of skeletal maturation, sexual development and somatic growth in man. Ann. hum. Biol. 1, 29-40.

MARShALL, W.A. \& LIMOGNI, Y. (1976) Skeletal maturity and prediction of age at menarche. Ann. hum. Biol. 3, 235-243.

MARShall, W.A. \& TANNER, J.M. (1969) Variations in the pattern of pubertal changes in girls. Archs Dis. Childh. 44, 291-303. 
Marshall, W.A. \& TANNeR, J.M. (1970) Variations in the pattern of pubertal changes in boys. Archs Dis. Childh. 45, 13-25.

Mellits, E.D. \& CHEEK, D.B. (1970) The assessment of body water and fatness from infancy to adulthood. Mon. Soc. Res. Child Dev. 35, 12-27.

Osler, D.C. \& CRAWFord, J.D. (1973) Examination of the hypothesis of a critical weight at menarche in ambulatory and bedridden mentally retarded girls. Pediatrics 51, 675-679.

TANNER, J.M. (1962) Growth at Adolescence, 2nd edn. Blackwell, Oxford.
TANNER, J.M. (1965) Radiographic studies of body composition in children and adults. Symp. Soc. Stud. Hum. Biol. 6, 211-236.

TANNer, J.M., Whitehouse, R.H., Marshall, W.A., HeAley, M.J.R. \& Goldstein, H. (1975) Assessment of Skeletal Maturity and Prediction of Adult Height (TW2 Method). Academic Press, London.

Young, C.M., SiPIN, S.S. \& Roe, D.A. (1968) Body composition of pre-adolescent and adolescent girls. J. Am. Diet. Ass. 53, 357-362. 